\title{
Mechanical behavior and microstructure evolution of a quenched and partitioned steel during drop weight impact and punch testing
}

\author{
Peikang. Xia ${ }^{\text {a, b, *, Ilchat Sabirov }}{ }^{\text {a }}$, Jon Molina-Aldareguia a, \\ Patricia Verleysen ${ }^{\mathrm{c}}$, Roumen Petrov ${ }^{\mathrm{c} d}$
}

a IMDEA Materials Institute, Calle Eric Kandel 2, Getafe, 28906 Madrid, Spain

${ }^{\mathrm{b}}$ Universidad Politécnica de Madrid, E.T.S. de Ingenieros de Caminos, 28040 Madrid, Spain

${ }^{c}$ Department of Electrical Energy, Metals, Mechanical constructions \& Systems, Research group Materials Science and Technology, Ghent University, Technologiepark 903, 9052 Gent, Belgium

${ }^{\mathrm{d}}$ Delft University of Technology, Department of Materials Science and Engineering, Mekelweg 2, 2628, CD Delft, The Netherlands

\footnotetext{
Abstract

In this work, a Fe-0.25C-3.0Mn-1.5Si-0.023 Al-0.015Cr (wt. \%) steel was subjected to the $\mathrm{Q} \& \mathrm{P}$ treatment, and its mechanical behavior and microstructure evolution during drop weight impact testing and quasi-static punch testing were thoroughly analyzed. It is shown that the $1 \mathrm{~mm}$ thick Q\&P steel sheet can withstand $110 \mathrm{~J}$ impact energy without any (micro) cracking, which is well above the impact resistance of DP 1180 steel. The local true plastic strain can reach 53.4\% in biaxial stretching showing excellent formability of the material. The microstructure

* Corresponding author.

Peikang Xia, IMDEA Materials Institute, Calle Eric Kandel 2, Getafe, 28906, Madrid, Spain.

Phone: +34915493422

E-mail addresses: xia.peikang@imdea.org, xia.peikang@gmail.com
} 
characterization shows that the volume fraction of retained austenite decreases exponentially with increasing plastic strain under dynamic biaxial stretching. Scanning electron microscopy analysis of cracks formed after drop weight impact testing with $120 \mathrm{~J}$ energy reveals a ductile fracture surface consisting of elongated dimples formed by $\mathrm{MnS}$ inclusions which are surrounded by fine chisel-point type dimples. The potential of Q\&P treated steels for application in the automotive industry is discussed.

Keywords: Advanced high strength steels; quenching and partitioning; impact resistance; microstructure, retained austenite

\section{Introduction}

Motivated by the requirements of decreasing car body weight and improving passenger's safety and fuel efficiency, automobile manufacturers keep paying attention to newly developed materials, especially advanced high strength steels (AHSS) [1]. In the past decades, several innovative AHSS such as dual phase (DP) steels [2], transformation induced plasticity (TRIP) steels [3], twinning induced plasticity (TWIP) steels [4], and quenched and partitioned (Q\&P) steels [5] have been explored, and some of them have already been commercialized for fabrication of vehicle components. Among these AHSSs, Q\&P steels composed of a martensite matrix and retained austenite are one of the newest and most promising grades, which have attracted tremendous interest since they were first proposed in 2003 [5]. Although mechanical properties of Q\&P steels under tension [6], compression [7] and fatigue [8] have already been investigated, other properties like impact resistance have never been reported. On the other hand, in case of car crash accidents, the car body

parts should be capable of absorbing high impact energy to ensure safety of passengers. Consequently, it is of great importance to investigate the impact resistance 
of Q\&P steels and the effect of microstructure on their crashworthiness.

The Q\&P concept for heat treatment of steels was proposed by Speer et al. in 2003 [5]. In a Q\&P cycle, the fully austenitized or intercritically annealed steel is first quenched to a temperature between $\mathrm{M}_{\mathrm{s}}$ (martensite start) and $\mathrm{M}_{\mathrm{f}}$ (martensite finish) to form a defined fraction of martensite. In the second step, the steel is either held at this temperature or heated to a somewhat higher partitioning temperature. Diffusion of carbon from the supersaturated martensite into untransformed austenite in the second step enables its stabilization during final quenching to room temperature. This treatment leads to the formation of a complex multiphase microstructure consisting of: 1) tempered martensite (TM), formed during the first quenching and tempered in the partitioning step; 2) untempered martensite (UM), formed in the last quenching from inadequately carbon enriched austenite; and 3) metastable austenite retained in the last quenching. Additionally, ferrite is also present in the intercritically annealed steels. Size, volume fraction and morphology of all microconstituents are determined by chemistry and Q\&P treatment parameters. A significant body of research on their effect on microstructure and mechanical properties exists in the current literature. A wide range of Fe-based alloys, including stainless steel [9], TRIP steel [10], martensite steel [11], etc., have been proven to be potential candidates for Q\&P processing. Furthermore, the idea of Q\&P has also been extended to the quenching-partitioning-tempering (Q-P-T) process [12], in which a tempering step has been added following the $\mathrm{Q} \& \mathrm{P}$ procedure to add precipitation strengthening. Manipulation of the complex microstructure of the Q\&P steels can result in a very wide range of tensile strength and ductility. For example, ultimate tensile strengths in the range of $1267-1471 \mathrm{MPa}$ and elongations to failure in the range of $21-29 \%$ have been reported for a $0.25 \mathrm{C}-1.5 \mathrm{Si}-3 \mathrm{Mn}-0.023 \mathrm{Al}$ steel, as a function of partitioning temperature and time [13]. Strain partitioning of Q\&P steels strongly depends on their microstructure. Diego-Calderón et al. [14] performed in situ testing of $\mathrm{Q} \& \mathrm{P}$ steels combined with digital image correlation analysis of plastic strain distribution. A very inhomogeneous distribution of local plastic strain between phase microconstituents was demonstrated on the studied Q\&P steels. A maximum plastic 
strain of $\sim 8 \%$ was observed in the hard phases, while the soft phase accumulated up to $33 \%$, when the global strain reached $23 \%$.

For a steel grade targeted for automotive applications, its impact resistance and high strain rate behavior should be comprehensively understood. However, the amount of research reports on impact behavior of AHSSs is limited. In [15], Rodríguez-Martínez et al. studied the impact behavior of a TRIP 1000 steel employing drop weight testing with impact velocities of $2.5 \sim 4.5 \mathrm{~m} / \mathrm{s}$ at temperatures of $213 \mathrm{~K}$ and $288 \mathrm{~K}$. The results showed that the energy absorption increased with decreasing temperature, which was not related to the martensitic transformation but to the temperature sensitivity of the material. In [16], Rodríguez-Martínez et al. compared the impact resistance of AISI 304 and TRIP 1000 steels. They concluded that the superior performance of the AISI 304 steel at high speed loading stems from its high work hardening and ductility under dynamic conditions, and that this behavior was enhanced through martensitic transformation. Khan et al. [17] comparatively investigated the impact performance of various spot welded AHSSs and reported that the partial interfacial failure was the failure mode for welded TRIP 780 and high strength low alloy steel. No data on impact resistance of Q\&P treated steels can be found in the current literature. The current knowledge is limited to impact toughness of the Q\&P treated steels. Particularly, in [18] it was shown that Q\&P treatment of a high-Si steel leads to better impact toughness compared to other traditional heat treatments. Similar results were demonstrated in [19].

The main goal of this study is to examine the resistance, mechanical behavior and microstructure evolution of Q\&P steels under impact loading via drop weight testing. Unlike the Charpy testing, drop weight testing is performed on un-notched samples and, therefore, it is more relevant for materials used in body in white of cars.

\section{Material and experimental procedures}

\subsection{Material and thermo-mechanical processing}

The chemical composition of the steel is shown in Table $1.0 .25 \%$ carbon was 
added to gain sufficient austenite fraction and stability [20]. Moreover, the $3.0 \%$ manganese provides further stability and hardenability to austenite [21]. To suppress carbide precipitation during $\mathrm{Q} \& \mathrm{P}$ heat treatment, the steel was alloyed by $1.5 \%$ silicon [22]. Finally, a small amount of aluminum and chromium were added for carbide suppression and hardenability enhancement according to [23,24].

Table 1. Chemical composition (wt. \%) of the steel.

\begin{tabular}{ccccc}
\hline $\mathrm{C}$ & $\mathrm{Mn}$ & $\mathrm{Si}$ & $\mathrm{Al}$ & $\mathrm{Cr}$ \\
\hline 0.25 & 3.0 & 1.5 & 0.023 & 0.015 \\
\hline
\end{tabular}

The steel was casted in a laboratory vacuum induction furnace. The steel slabs were hot rolled to a final thickness of $2.5 \mathrm{~mm}$, followed by water jets cooling to $600{ }^{\circ} \mathrm{C}$. Then, they were transferred to a furnace for coiling simulation at $560{ }^{\circ} \mathrm{C}$. At the last step, the steel sheets were pickled and cold rolled to a final thickness of $1 \mathrm{~mm}$. The rolled steel was cut perpendicular to the rolling direction for heat treatment. The Q\&P process was carried out in a reactive annealing process simulator following the thermal cycle presented in Fig. 1. First, the steel was heated to $850{ }^{\circ} \mathrm{C}$ and soaked for $60 \mathrm{~s}$ for full austenitization and then quenched to $244{ }^{\circ} \mathrm{C}$ (quenching temperature, QT) with a cooling rate of $20{ }^{\circ} \mathrm{C} / \mathrm{s}$. Subsequently, the steel was reheated to $400{ }^{\circ} \mathrm{C}$ (partitioning temperature, PT) with the heating rate of $20^{\circ} \mathrm{C} / \mathrm{s}$ and kept for $500 \mathrm{~s}$. Finally, after the partitioning step, the steel sheets were quenched to room temperature at $20{ }^{\circ} \mathrm{C} / \mathrm{s}$. The ultimate tensile strength and elongation to failure of the Q\&P processed sheet are $1267 \mathrm{MPa}$ and $27.5 \%$, respectively [13]. 


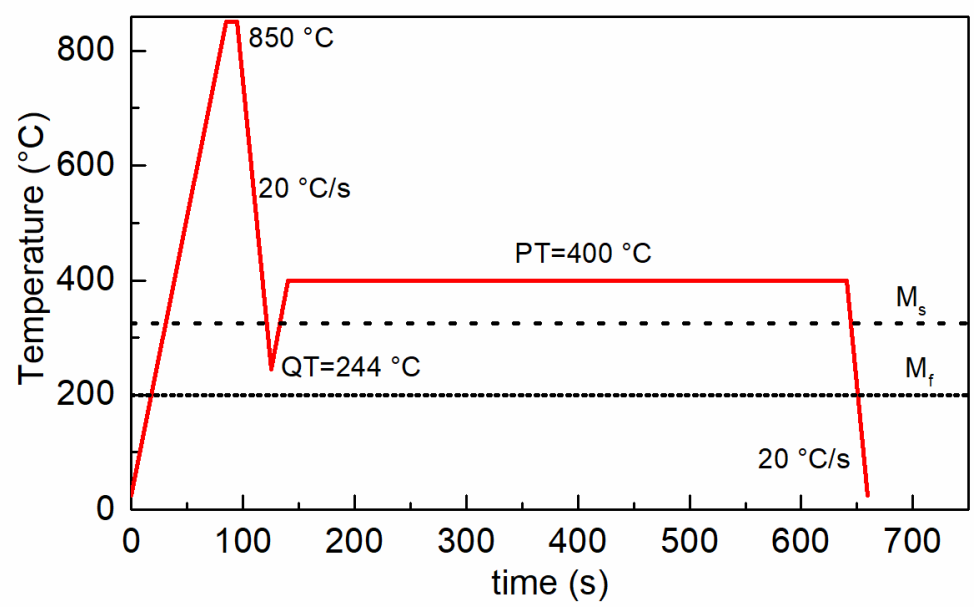

Fig. 1. Schematic illustration of the Q\&P heat treatment cycle applied to the studied steel. The $\mathrm{M}_{\mathrm{s}}=320{ }^{\circ} \mathrm{C}$ and $\mathrm{M}_{\mathrm{f}}=200{ }^{\circ} \mathrm{C}$ were determined earlier by dilatometry measurements.

\subsection{Drop weight impact testing and quasi-static punch testing}

To investigate the impact resistance of the Q\&P steel, a drop weight impact testing system (INSTRON CEAST 9350) was employed. For quasi-static punch testing in the same mode, a universal electromechanical testing machine (INSTRON 3384) was used. The $50 \times 50 \times 1 \mathrm{~mm}$ samples were cut for both drop weight impact and quasi-static punch testing (Fig. 2(b)). The same hemispherical punch with a diameter of $16 \mathrm{~mm}$ was employed for both types of testing. The punch is made of hard alloy steel having a hardness of 60 HRC. During quasi-static punch testing, the sample was fixed effectively by a house-made holder with bolts (as shown in Fig. 2(a)), while in drop weight testing the specimen was clamped by a pneumatic system. The shape and size of the holder and fastening components used in both kinds of test were the same. A multipurpose lubricant (Super Lube, Syncolon ${ }^{\circledR}$ ) was applied to the punch surface to minimize frictional dissipated energy. The purpose of limiting these foregoing conditions is to obtain biaxial stress mode (nearly) in the center area of the specimen in both cases. The drop weight varied in the range of $4.3 \mathrm{~kg}$ to $9.8 \mathrm{~kg}$ depending on the impact energy. The applied impact energy and drop speed were in the range of 30 $\sim 120 \mathrm{~J}$ and $3 \sim 7 \mathrm{~m} / \mathrm{s}$, respectively, depending on the drop weight and height before test. To measure the adiabatic heating during drop weight impact, additional tests with 
a $K$-type thermocouple welded on the center of square shaped specimens were carried out, and the maximum temperature achieved during testing was recorded. It should be noted that to compare the energy absorption capability of the studied Q\&P steel with other AHSS, $1 \mathrm{~mm}$ thickness commercial sheets of AISI 304 stainless steel (Fe-0.08C-18Cr-9.0Ni-2.0Mn-1.0Si in wt.\%) and DP 1180 steel (Fe-0.23C-3.0Mn-0.6Si in wt.\%) were also tested using this system drop weight impact system.

Quasi-static punch testing of the Q\&P steel with two punch speeds of $8.33 \times 10^{-5}$ and $8.33 \times 10^{-7} \mathrm{~m} / \mathrm{s}$ was performed until the formation of $\operatorname{crack}(\mathrm{s})$. The load-displacement curves were recorded during both types of testing.

A

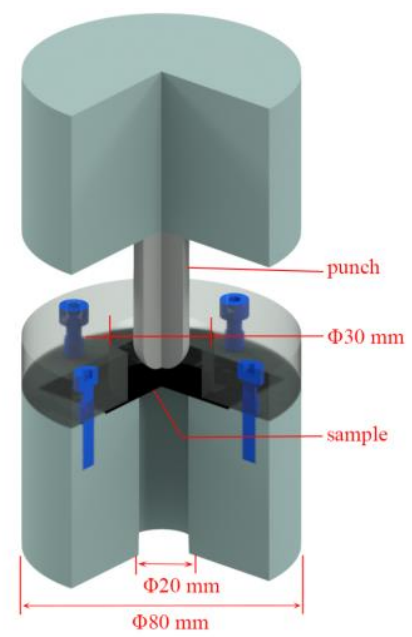

B

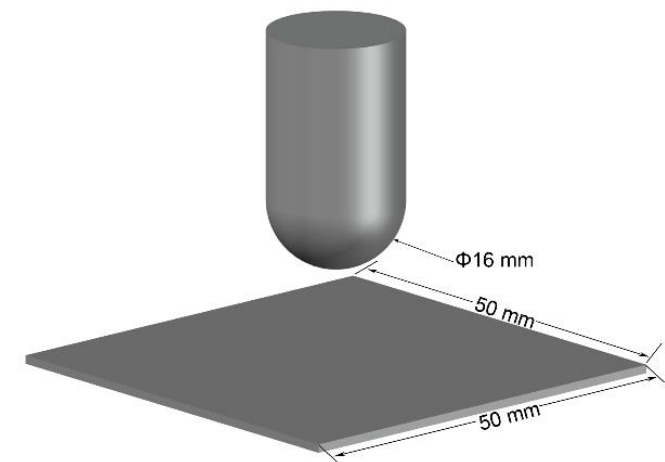

Fig. 2. (a) Schematic diagram of drop weight impact and quasi-static punch tests, sectioned by a quarter. (b) Geometry of specimen and punch used in both drop weight impact testing and quasi-static punch testing.

Fig. 3 (a) schematically shows samples after drop weight impact and quasi-static punch testing. The true plastic strain induced into the sheet at the top of the hemi-sphere was estimated by measuring the thickness before and after testing, as shown in Fig. 3(a) from [25]:

$$
\varepsilon=\ln \frac{h_{o}}{h_{f}}
$$

where $\varepsilon$ is the true strain, $h_{o}$ is the original thickness and $h_{f}$ is the thickness after 
testing, respectively. Typical hemi-spherical section profiles of deformed samples after drop weight impact and quasi-static punching are shown in Fig. 3(b) and (c). The radial strain distribution along over the dome was analyzed using equation (1).
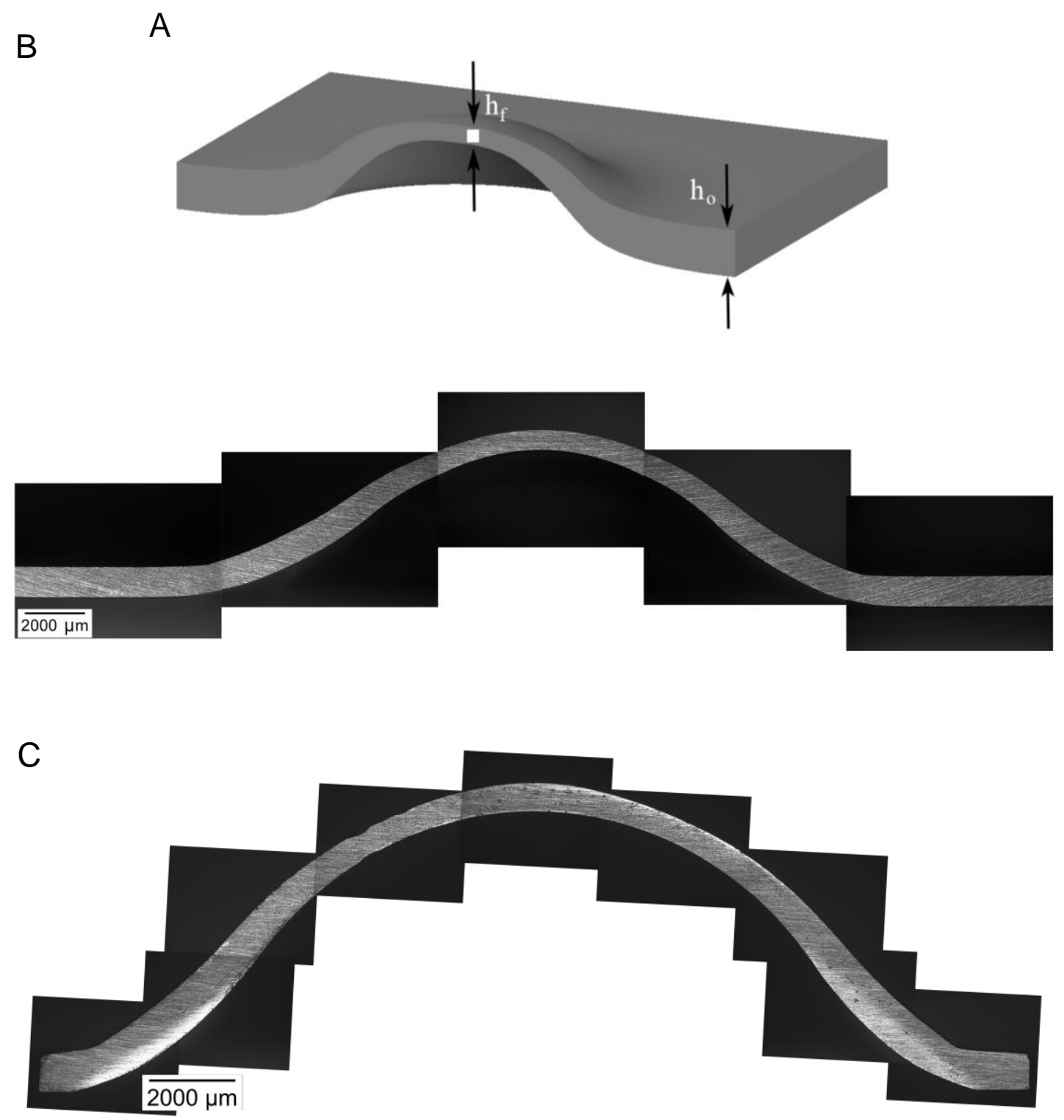

Fig. 3. (a) Schematic illustration of thickness measurements after testing and the position of area selected for EBSD characterization (marked by white square). (b) Typical section profile of sample after drop weight impact testing $(90 \mathrm{~J}, 4.06 \mathrm{~m} / \mathrm{s})$. (c) Typical section profile of specimen after quasi-static punch testing $\left(8.33 \times 10^{-5} \mathrm{~m} / \mathrm{s}\right)$.

\subsection{Microstructural analysis}

After drop weight impact and quasi-static punch testing, the microstructures and 
fracture surfaces (for cracked samples) were carefully examined. A field emission gun scanning electron microscopy (Helios NanoLab 600i, FEI) operating at a voltage of $15 \mathrm{kV}$ and a current of $0.69 \mathrm{nA}$ was employed to characterize the fracture surfaces of cracked samples after both types of testing. To analyze the microstructure evolution during deformation, electron back-scatter diffraction (EBSD) analysis was carried out on the same microscope equipped with a NordlysNano detector controlled by the Aztec Oxford Instruments Nanoanalysis software (version $4.2^{\circledR}$ ). For EBSD characterization, the top part of the hemi-sphere (corresponding to the area marked by the white square in Fig. 3(a)) was cut from the tested specimens, ground following a standard metallographic procedure and polished with OP-S for 10 minutes at the final step. EBSD analysis was performed on the RD-ND plane and mid-section of the tested sheet, where biaxial stretching mode prevails. Kikuchi patterns were collected at an accelerating voltage of $18 \mathrm{kV}$, a working distance of $8 \mathrm{~mm}$ and a step size of 50 $\mathrm{nm}$ in square scan grid. The EBSD data were post-analyzed using HKL Channel 5 software (version $5.1^{\circledR}$ ). Kernel Average Misorientation (KAM) maps were calculated with respect to the third nearest neighbors using the HKL software for each specimen. This is an effective EBSD-based approach to analyze local micro-deformation by means of calculating the orientation difference between point clusters [26]. Histograms of statistical distribution of plastic microstrain in the analyzed microstructure were generated based on the KAM map for each specimen.

Chemical analysis of inclusions was carried out using an Oxford Inca 350 Energy Dispersive Spectrometer (EDS) embedded in the field emission gun scanning electron microscope at operating voltage of $15 \mathrm{kV}$ and working distance of $5 \mathrm{~mm}$.

\section{Results}

3.1. Mechanical behavior of the material during drop weight impact and quasi-static punch testing 
Typical views of samples after drop weight and static punch testing are presented in Fig. 4. Careful analysis using microscopy did not reveal the presence of any (micro) cracks on surface of specimens tested with impact energies of 30 - $110 \mathrm{~J}$ (Fig. 4(a)). Large crack along rolling direction was observed only in the specimens tested with $120 \mathrm{~J}$, and just in the center of the hemisphere shell. On the other hand, in quasi-static punch tests, cracks occurred on the side of the hemisphere shell (Fig, 4(b)), under shearing (incomplete biaxial) stress state.
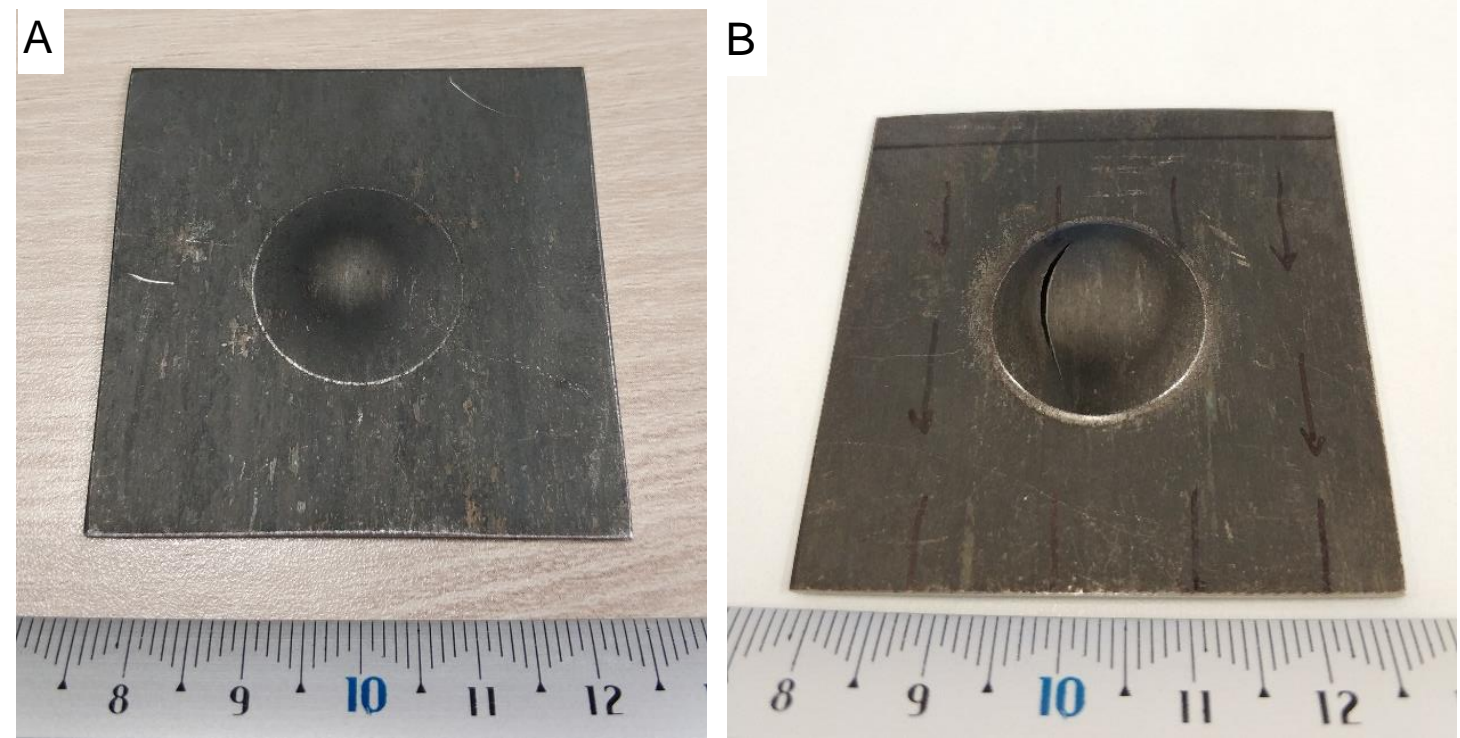

Fig. 4. Typical views of samples (a) uncracked after drop weight impact test (90 J impact energy) and (b) cracked on the side after quasi-static punch test (punch speed $\left.8.33 \times 10^{-7} \mathrm{~m} / \mathrm{s}\right)$. Arrows indicate the rolling direction.

The force-displacement curves from drop weight impact and static punch testing are shown in Fig. 5(a). The punch speed has been unified to $\mathrm{m} / \mathrm{s}$ for easier comparison. For drop weight impact tests $(3 \sim 7 \mathrm{~m} / \mathrm{s})$, all the curves look similar, and the load increases with increasing displacement (i.e. central deflection) and rebounds back to zero after reaching the peak load. However, the curve corresponding to the sample impacted with the maximum energy of $120 \mathrm{~J}$ (with a drop speed of $6.74 \mathrm{~m} / \mathrm{s}$ ) shows a swing phenomenon in its descending part. This observation can be related to formation of $\operatorname{crack}(\mathrm{s})$, which was seen only in the samples impacted with $120 \mathrm{~J}$. Thus, it can be concluded that the studied $1 \mathrm{~mm}$ thick Q\&P steel sheet can withstand $110 \mathrm{~J}$ 
impact energy.

The true plastic strain measured at the top of the hemi-spherical part of drop weight tested samples is shown in Fig. 5(b). The true plastic strain increases linearly with the impact energy. The true plastic strain in the sample impacted with $30 \mathrm{~J}$ was $14.0 \%$, while for an impact energy of $110 \mathrm{~J}$, the true plastic strain was $53.4 \%$. In the samples after punch testing with speeds of $8.33 \times 10^{-5}$ and $8.33 \times 10^{-7} \mathrm{~m} / \mathrm{s}$, the achieved values of true plastic strain were $41.4 \%$ and $53.7 \%$, respectively.
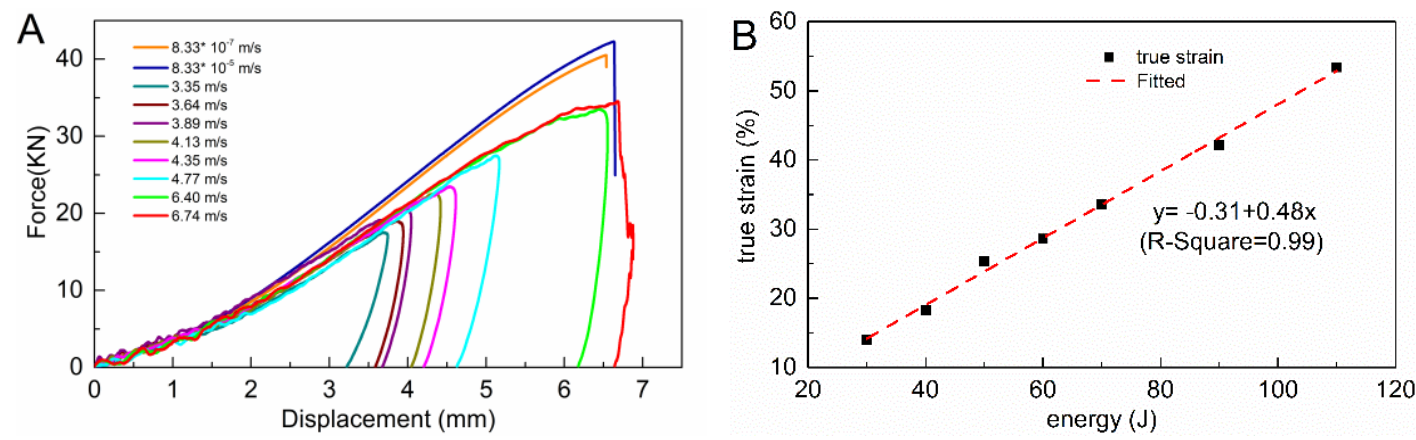

Fig. 5. (a) Force-displacement curves from drop weight impact and quasi-static punch testing; (b) Dependence of the true plastic strain with the impact energy in samples after drop weight testing. (For interpretation of the references to color in this figure legend, the reader is referred to the Web version of this article.)

\subsection{Microstructure evolution}

The microstructure of the as-received material is shown in Fig. 6(a), where retained austenite, tempered martensite and untempered (fresh) martensite can be identified. Two types of retained austenite are seen in the EBSD maps: large blocky retained austenite grains and the interlath lamellar-type one. The fraction of retained austenite in the Q\&P treated steel measured by EBSD was $9.6 \%$ which is less than the value measured by X-ray diffraction on the same material, $18 \%$, reported earlier by Diego- Calderón et al. in [13]. The difference between the volume fractions determined by XRD and EBSD is related to the presence of very thin film-type retained austenite having a thickness of 10-20 nm, which cannot be detected by EBSD $[27,28]$. The two types of martensite, tempered martensite and untempered martensite 
can be identified on EBSD maps due to their difference in band contrast. As seen in Fig. 6(a), untempered martensite is darker than tempered martensite due to higher density of lattice defects which decreases its Kikuchi pattern quality. A significant effect of impact testing on the microstructure of the material is clearly seen from Fig. 6(a) to (d). The initially equiaxed grains are biaxially stretched in the RD-TD plane. The band contrast is reduced and grain boundaries become blurry (as shown in Fig. 6(c) and (d)) due to increased dislocation density, which can be reflected indirectly from Kernel Average Mmisorientation (KAM) (see Fig. 9).
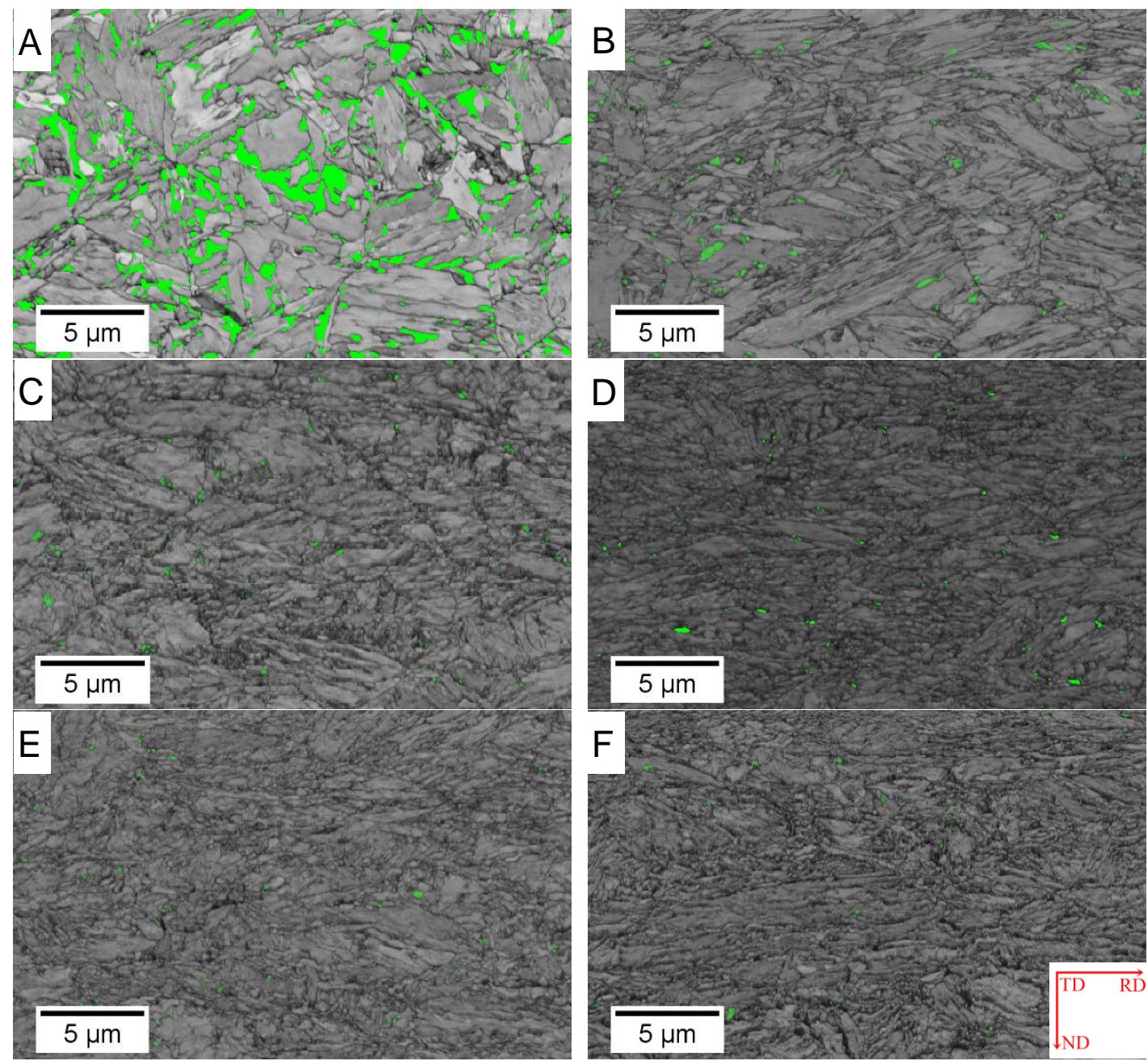

Fig. 6. Band contrast map (with gray color) and retained austenite phase map (with green color) of the tested specimens as a function of true plastic strain in different conditions: (a) original non-deformed material; (b) $28.6 \%$ (4.77 m/s, $60 \mathrm{~J})$; (c) $42.2 \%$ 
$(4.06 \mathrm{~m} / \mathrm{s}, 90 \mathrm{~J})$; (d) $53.4 \%(6.40 \mathrm{~m} / \mathrm{s}, 110 \mathrm{~J}) ;$ (e) $42.2 \%\left(8.33 \times 10^{-5} \mathrm{~m} / \mathrm{s}\right.$, punch testing); (f) $53.7 \%\left(8.33 \times 10^{-7} \mathrm{~m} / \mathrm{s}\right.$, punch). The horizontal plane is parallel to the RD. (For interpretation of the references to color in this figure legend, the reader is referred to the Web version of this article.)

The volume fraction of retained austenite in samples after drop weight testing tends to decrease with increasing true plastic strain, from the initial $9.6 \%$ to a saturation value of $\sim 0.7 \%$ after reaching a true plastic strain of $42.2 \%$ (corresponding to an impact energy of $90 \mathrm{~J}$ ). The volume fraction of retained austenite as a function of true plastic strain follows an exponential function with a correlation coefficient of $\mathrm{R}^{2}=0.99$, and the fitting parameters presented in Fig. 7. Based on the fitting curve, it can be hypothesized that $0.58 \%$ of retained austenite would remain untransformed with further increasing strain.

The microstructure of the samples after punch testing (Fig. 6(e) and (f)) is similar to that of the sample after $110 \mathrm{~J}$ impact testing. The volume fraction of retained austenite in the specimens tested at $8.33 \times 10^{-5}$ and $8.33 \times 10^{-7} \mathrm{~m} / \mathrm{s}$ was $0.44 \%$ and $0.35 \%$, respectively, which is close to that in the specimen after $110 \mathrm{~J}$ impact testing (Fig. 7).

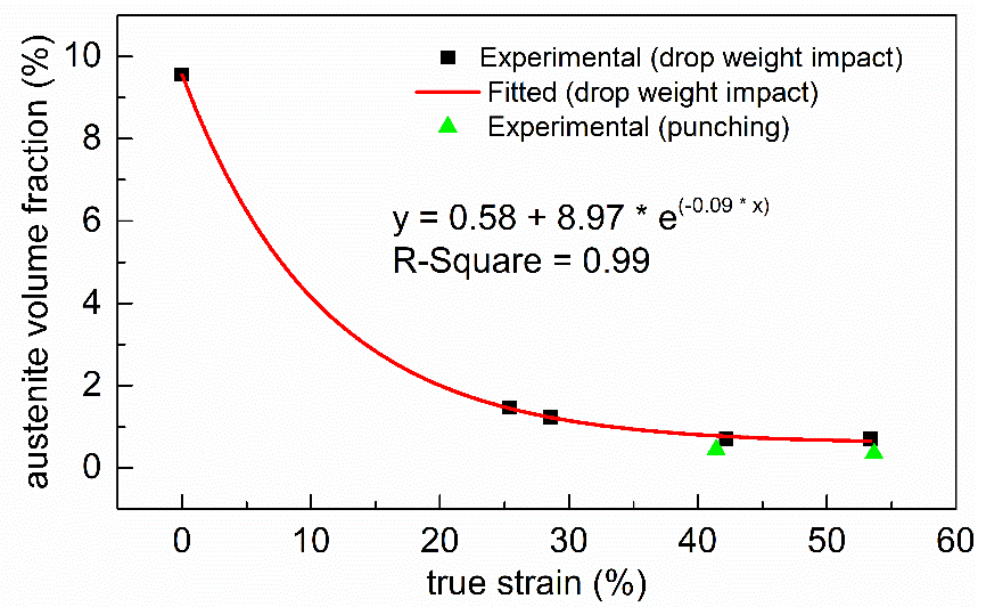

Fig. 7. Relationship between volume fraction of retained austenite and true plastic strain in the samples after drop weight impact and punch testing. 
KAM is an effective EBSD-based approach to analyze local micro-deformation. Typical KAM maps for the undeformed specimen and specimen after drop weight impact testing with $110 \mathrm{~J}$ energy (strain, 53.40\%) are shown in Fig. 8(a) and Fig. 8(b), respectively. Histograms of distribution of misorientation in the martensite and austenite generated from the KAM maps of different specimens are compared in Figure 9. It is seen from Fig. 8a that in the underformed material, the interior of grains in tempered martensite matrix and retained austenite has near zero local misorientation, while higher local misorientations up to $\sim 1.5^{\circ}$ are observed in the areas corresponding to untempered martensite and at grain boundaries due to local deformation induced by phase transformation. After drop weight testing with increasing plastic strain, the curves for both martensite and austenite are gradually shifted towards higher misorientations due to increasing density of defects. Local misorientations of $0.8-2.5 \%$ prevail in the KAM map for tempered martensite in the $110 \mathrm{~J}$ sample (Fig. 8(b)), which might be related to formation of a cell structure in the grain interior (Fig. 6(d)) due to the very high plastic strain induced into material, $53.4 \%$. It should be noted that the latter sample presented slightly lower misorientations than those for the punch tested samples, despite all of them presented very similar values of true plastic strain (Fig. 9(a)). A similar phenomenon can be found in the KAM maps of retained austenite in Fig. 9(b) as well. It should be noted that the histograms of misorientation distribution in the martensite and retained austenite of specimens after quasi-static testing are similar to those in the specimens after drop weight testing to the same plastic strain (Figure 9).
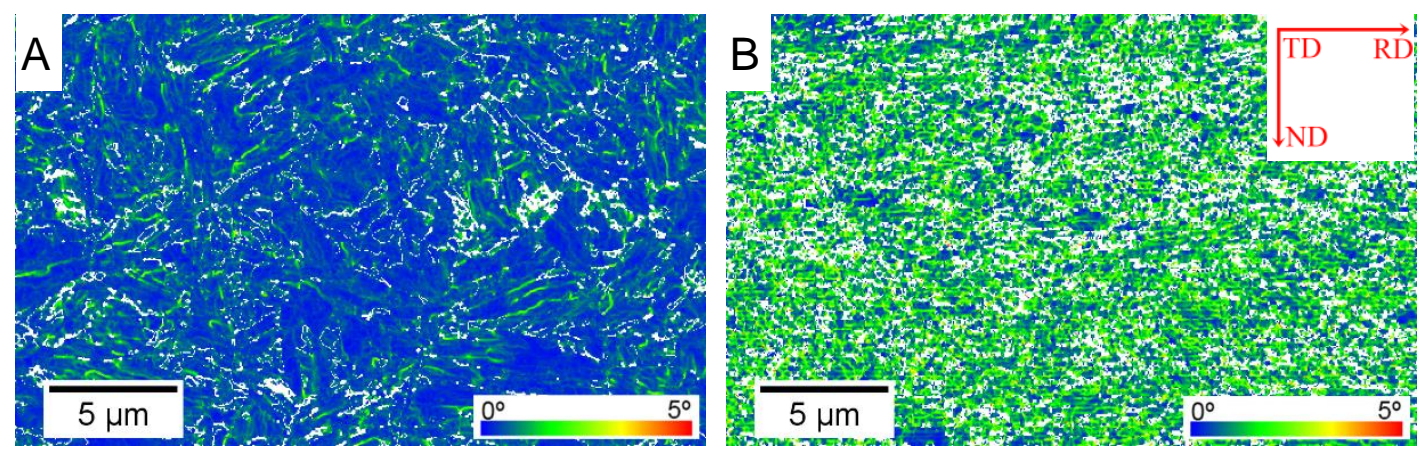

Fig. 8. Typical KAM maps of the Q\&P steel at different conditions: (a) undeformed; 
(b) after drop weight impact testing with $110 \mathrm{~J}$ energy (strain, 53.40\%). White pixels correspond to the points with low indexation reliability. (For interpretation of the references to color in this figure legend, the reader is referred to the Web version of this article.)
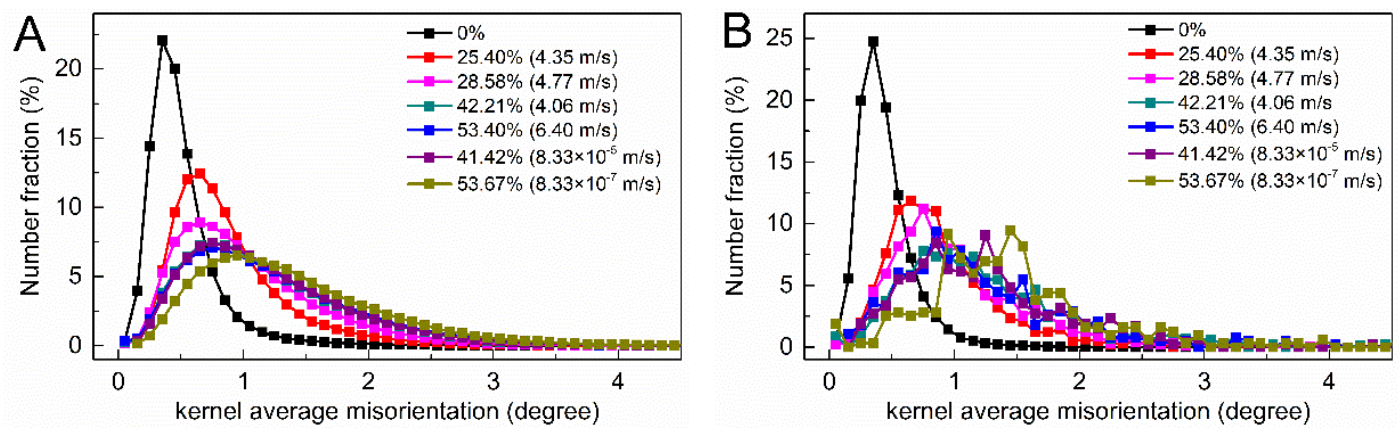

Fig. 9. KAM statistical distribution of (a) martensite and (b) retained austenite for samples before and after testing with different parameters. (For interpretation of the references to color in this figure legend, the reader is referred to the Web version of this article).

\subsection{Cracking}

The fracture surfaces of cracked samples after drop weight and quasi-static punch testing were carefully examined by SEM. In Figs. 10(a-d) fracture surfaces of a sample after drop weight testing is presented. As can be seen from Fig. 10(a), they are characterized by the presence of dimples, thus indicating ductile failure of the material, and elongated microcracks having a length of several hundred micrometers. The long microcracks are parallel to the rolling direction. Block-like manganese sulfide (MnS) inclusions were detected by EDS inside the microcracks (Fig. 10(b)). It is well known that MnS inclusions serve as nucleation sites and propagation pathways for long microcracks in steels [29]. The morphology of the dimples on the fracture surface shown in Fig. 10(d) is typical for those formed during ductile fracture. The fractography of static punch tested specimens is shown in Fig. 10(e) to (h). Samples after quasi-static punch testing at both speeds show similar fracture surfaces composed of long microcracks formed by $\mathrm{MnS}$ inclusions and 'dimples'. The 
morphology of the long microcracks is similar to that observed in the sample after drop weight impact tests. The morphology of the dimples is illustrated in Fig. 10(f) and (h), where two types of dimples can be identified. First type of dimples (marked by solid circle in Fig. 10(f)) is similar to that observed on the fracture surface of specimens after drop weight impact tests (Fig. 10(d)). The second type of dimples (marked by dashed circle in Fig. 10(f)) presents smooth cleavage-like facets indicating local shearing failure. This observation can be related to the crack formation on the side of the hemisphere shell, where a shearing component is present in the stress mode (see Section 4.3).
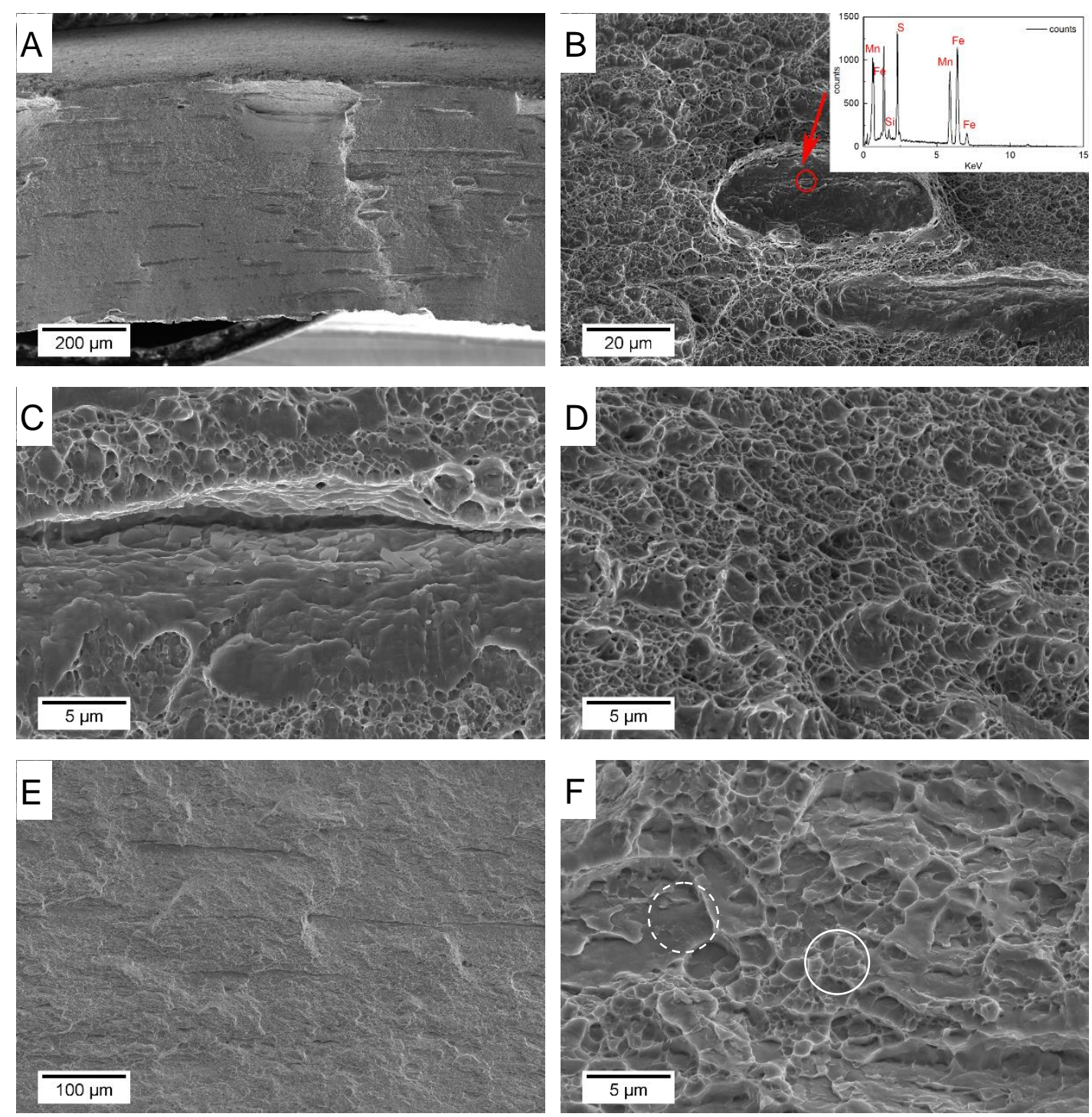

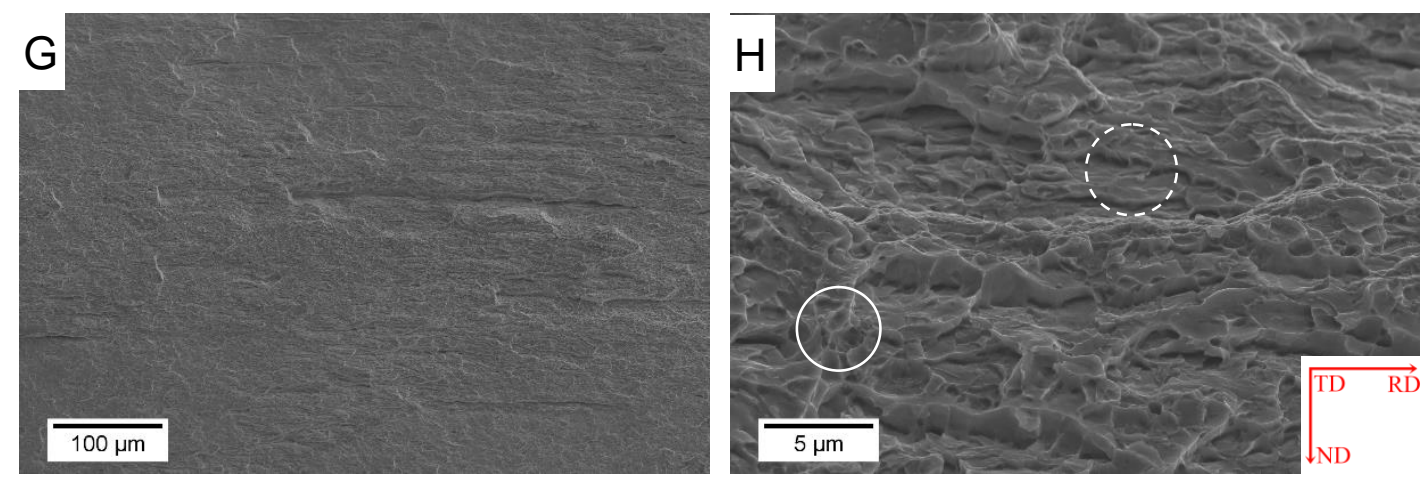

Fig. 10. SEM fracture surface of cracked specimens tested at different conditions: (a d) after drop weight impact with $120 \mathrm{~J}$; (e, f) after quasi-static punch test with speed of $8.33 \times 10^{-5} \mathrm{~m} / \mathrm{s} ;(\mathrm{g}, \mathrm{h})$ after quasi-static punch test with speed of $8.33 \times 10^{-7} \mathrm{~m} / \mathrm{s}$.

\section{Discussion}

\subsection{Effect of strain rate on energy absorption capability}

To compare the maximum energy absorption capability of the Q\&P steel during drop weight impact and quasi-static punch testing, the areas under the load-displacement curves was calculated [30], since it determines the energy absorbed in these processes. The calculation outcomes along with the corresponding true plastic strain values are listed in Table 2. The sample tested at $6.46 \mathrm{~m} / \mathrm{s}$ was not fractured at the end of the test, so the energy given in Table 2 gives an under limit for the energy absorption capacity of the sample. The average strain rate was estimated as a ratio of the measured plastic strain to time. It is seen that the energy consumed by the $1 \mathrm{~mm}$ sheet of the Q\&P steel at fracture in both static and dynamic tests is above $110 \mathrm{~J}$. In the meanwhile, the values of maximum energy withstood by AISI 304 and DP 1180 steels are $130 \mathrm{~J}$ and $90 \mathrm{~J}$, respectively. These experimental results will be published in a future article. It is clearly seen that the studied Q\&P steel shows enhanced crush resistance above that of the DP 1180 steel, though it is lower compared to the AISI 304 stainless steel. This capability should stem from the unique microstructure of the material. The high strength tempered martensite matrix is able to accumulate a high amount of plastic deformation without any (micro)cracking (Fig. 9(a)), while the retained austenite provides an extra ductility due to the TRIP effect (Fig. 8) as well as 
by bearing plastic deformation (Fig. 9(b)).

Another interesting observation is that the energies absorbed in quasi-static punch tests for both strain rates $(123 \mathrm{~J}$ and $131 \mathrm{~J})$ are higher than that in the drop weight impact tests $(114 \mathrm{~J})$, despite the strain rate being five to seven orders of magnitude higher in the latter case (Table 2). Thus, the ability of the material to absorb energy is lower at high strain rates (i.e. impact). This observation can be rationalized based on adiabatic heating effect. The Q\&P steel is locally weakened due to the softening effect of adiabatic heating on the martensitic matrix during drop weight impact test. It is clearly seen from the force-displacement curves in Fig. 4(a) that during quasi-static punch testing a higher force (i.e. stress) is required to achieve similar displacements, thus indicating a higher strength of the material. This is also confirmed by measurements of adiabatic temperature change. The maximum temperature recorded during $110 \mathrm{~J}$ impact testing was $187^{\circ} \mathrm{C}$, which should reduce the tensile strength of the material by $10-15 \%$ without any increase of ductility $[31,32]$. In the meanwhile, the heat generated in quasi-static punch testing flows into the punch and fixing elements keeping the specimen temperature constant.

Table 2. Test speed, calculated energy, true strain, strain rate and sample state for both drop weight impact and punch tests.

\begin{tabular}{ccccc}
\hline Test speed $(\mathrm{m} / \mathrm{s})$ & $\begin{array}{c}\text { Average strain } \\
\text { rate }\left(\mathrm{s}^{-1}\right)\end{array}$ & $\begin{array}{c}\text { Calculated } \\
\text { energy }(\mathrm{J})\end{array}$ & $\begin{array}{c}\text { True strain } \\
(\%)\end{array}$ & Sample state \\
\hline $8.33 \times 10^{-7}$ & $6.8 \times 10^{-5}$ & 123 & 53.7 & cracked \\
$8.33 \times 10^{-5}$ & $5.3 \times 10^{-3}$ & 131 & 42.3 & cracked \\
6.46 & 384 & 105 & 53.4 & uncracked \\
6.74 & 421 & 114 & $57.9^{*}$ & cracked \\
\hline
\end{tabular}

*value obtained via extrapolation of the fitting function in Fig. 5(b).

\subsection{Evolution of retained austenite}

In the present work, an exponential decrease of the volume fraction of retained austenite with increasing plastic strain during drop weight testing (i.e. in biaxial 
stretching) has been found (Fig. 7). It is well known that the stress state has a significant effect on stability of retained austenite during plastic deformation [33-35]. Particularly, the biaxial stretching promotes austenite transformation compared to uniaxial testing [35]. Similar investigations on the evolution of retained austenite under uniaxial tensile deformation were already carried out. By employing XRD, Hao et al. [36] measured the fraction of retained austenite in a Q-P-T steel as a function of plastic deformation under quasi-static uniaxial tension. The content of retained austenite decreased rapidly from $10.8 \%$ to less than $3.0 \%$ with increasing plastic strain to $11 \%$, indicating that martensitic transformation occurred extensively at the early stages of deformation. De Knijf et al. [37] studied the behavior of retained austenite in a Q\&P steel (with the same chemical composition and microstructure as the one in the current study) during quasi-static tensile testing. They also found an exponential decay of the volume fraction of retained austenite with increasing plastic strain. Therefore, the conclusion can be drawn that volume fraction of retained austenite decreases exponentially with plastic strain both under uniaxial and biaxial loading.

\subsection{Effect of strain rate on strain distribution in tested specimens}

The fracture surfaces of the specimens after impact and quasi-static punch testing show somewhat different morphologies. Long microcracks formed by $\mathrm{MnS}$ inclusions are present in both and chisel-point dimples dominating the fracture surface and indicating ductile failure. Generally, similar morphology of ductile fracture surface should indicate similar energy spent for its formation, according to the Stuwe model [38]. However, after integrating the force-displacement curves, we found that the studied Q\&P steel absorbed a higher amount of energy in quasi-static punch tests, as shown in Table 2. The following explanation is proposed for this observation. The measurements of the radial strain distribution over the dome (as shown in Fig. 11), show their different character in samples after drop weight impact and quasi-static punch testing. For drop weight impact tested specimens, the strain peak appears in the top of the dome (red line in Fig. 11), while for quasi-static punched samples, the dome 
top has lower strain than its surrounding area. This difference can be ascribed to the variation of friction coefficient with rising strain rate (i.e. contact speed). As confirmed previously by pin-on-disk wear testing [39], the friction coefficient between the puncher and specimen decreases with increasing speed. On the other hand, the friction condition can influence the strain distribution significantly during punch tests, i.e. high frictional force retards deformation in the top of dome causing less deformation there and more deformation in the unsupported areas [40,41]. A similar effect is observed in the present study. Figure 11 illustrates plastic strain distribution over the dome of samples tested by both methods. It is clearly seen that the decreasing strain rate shifted the strain peak from the top (red line on Fig. 11) toward the edge of the hemispherical dome (green line on Fig. 11). Therefore, samples tested by quasi-static punch method cracked in the area which is displaced to the side of the dome, where the highest amount of plastic strain was accumulated (Fig. 4(b)).

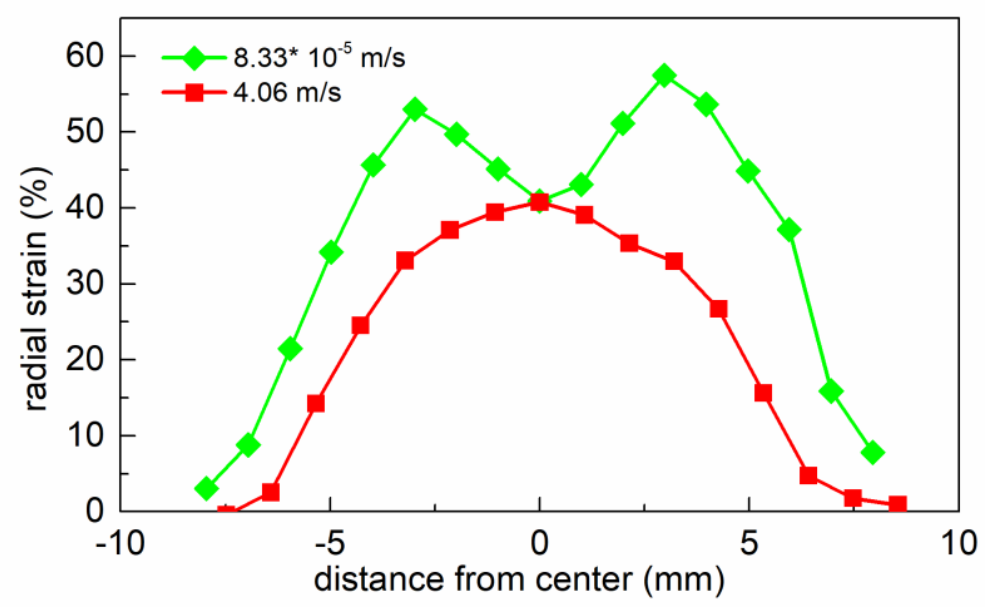

Fig. 11. Typical strain distribution over the dome of specimens after drop weight impact and quasi-static punch testing. (The curves of $8.33 \times 10^{-5} \mathrm{~m} / \mathrm{s}$ and $4.06 \mathrm{~m} / \mathrm{s}$ are for punch and drop weight impact (90 J) testing, respectively)

\subsection{Feasibility of $Q \& P$ steels for automotive applications}

As shown above, the studied Q\&P steel has a better impact resistance than the DP 1180 steel due to their unique microstructure. Despite the AISI 304 stainless steel shows somewhat better impact resistance, it cannot compete with the Q\&P steel due to its very high cost related to the expensive alloying elements and their high content. 
Furthermore, the studied Q\&P steel can accumulate higher plastic strain during quasi-static punch testing and absorb a higher amount of energy than during impact, showing a remarkable biaxial stretching formability, which is advantageous for automotive stamping. The improved formability of the present steel is provided by the martensitic matrix being able to accumulate a higher amount of plastic deformation (Fig. 8b) and by the TRIP effect provided by the retained austenite grains (Fig. 7). The latter has been well known for decades [42] as the effect of dislocation absorption of retained austenite (DARA) [43] during deformation, moderates possible local stress concentrations and delays crack propagation. The results show excellent prospects in automotive industry for this Q\&P steels. As it is well known, high strength combined with high formability is the main requirement for materials used for manufacturing of complex shape automotive parts such as B-pillar reinforcements and floor beams. There are already reports on these parts produced from high strength Q\&P steels with the aim of reducing car weight $[44,45]$ and relevant investigations about their industrial applications are on the way now [46-50]. This work demonstrates that another advantage of Q\&P steels for application in automotive sector lays on their enhanced crashworthiness, which improves the passenger safety.

\section{Conclusions}

The mechanical behavior, microstructure evolution and failure behavior of a quenched and partitioned (Q\&P) steel were investigated by employing drop weight impact testing and quasi-static punch testing. The following conclusions can be drawn:

1. In drop weight impact testing, the Q\&P steel (1 mm thick) can withstand at least an impact energy of $110 \mathrm{~J}$ without cracking, with the steel accumulating a true plastic strain of 54\%. The Q\&P steel showed a better impact resistance than DP 1180 steel.

2. The Q\&P steel has a slightly better energy absorption capability during quasi-static punch testing than during drop weight impact testing. This is mainly 
related to the softening of the material induced by adiabatic heating during impact testing.

3. The volume fraction of retained austenite decreases exponentially with increasing plastic strain during biaxial stretching, similarly to what has been reported before for uniaxial tensile deformation.

4. In drop weight impact tests, the specimens cracked at the top of hemisphere, while the failure position of specimens tested by quasi-static punch method was displaced to the side of the dome. This observation is related to the higher friction coefficient during quasit-static punch testing, which retards plastic deformation on the top of the dome and shifts the peak strain to the side.

\section{Acknowledgements}

This work was financially supported by the RFCS project OptiQPAP (GA $\mathrm{N}^{\mathrm{0}}$ 709755). PX acknowledges the financial supporting from Chinese Scholarship Council (No. 201606890031). IS and JMMA acknowledge gratefully the financial support by Madrid region under program S2013/MIT-2775, DIMMAT project.

\section{Reference}

[1] R. KUZIAK, R. KAWALLA, S. WAENGLER, Advanced high strength steels for automotive industry, Arch. Civ. Mech. Eng. 8 (2008) 103-117. doi:10.1016/S1644-9665(12)60197-6.

[2] M. Sarwar, R. Priestner, Influence of ferrite-martensite microstructural morphology on tensile properties of dual-phase steel, J. Mater. Sci. 31 (1996) 2091-2095. doi:10.1007/BF00356631.

[3] P.J. Jacques, Transformation-induced plasticity for high strength formable steels, Curr. Opin. Solid State Mater. Sci. 8 (2004) 259-265. doi:10.1016/j.cossms.2004.09.006.

[4] O. Bouaziz, S. Allain, C.P. Scott, P. Cugy, D. Barbier, High manganese austenitic twinning induced plasticity steels: A review of the microstructure properties relationships, Curr. Opin. Solid State Mater. Sci. 15 (2011) 141-168. doi:10.1016/j.cossms.2011.04.002.

[5] J. Speer, D.K. Matlock, B.C. De Cooman, J.G. Schroth, Carbon partitioning into austenite after martensite transformation, Acta Mater. 51 (2003) 2611-2622. doi:10.1016/S1359-6454(03)00059-4.

[6] E. Paravicini Bagliani, M.J. Santofimia, L. Zhao, J. Sietsma, E. Anelli, Microstructure, tensile and toughness properties after quenching and partitioning treatments of a medium-carbon steel, Mater. Sci. Eng. A. 559 (2013) 486-495. doi:10.1016/j.msea.2012.08.130.

[7] F. Huang, J. Yang, Z. Guo, Y. Rong, N. Chen, Dynamic compression property of a low-carbon 
quenching and partitioning steel, Mater. Sci. Eng. A. 651 (2016) 224-232. doi:10.1016/j.msea.2015.10.115.

[8] I. de Diego-Calderón, P. Rodriguez-Calvillo, A. Lara, J.M. Molina-Aldareguia, R.H. Petrov, D. De Knijf, I. Sabirov, Effect of microstructure on fatigue behavior of advanced high strength steels produced by quenching and partitioning and the role of retained austenite, Mater. Sci. Eng. A. 641 (2015) 215-224. doi:10.1016/j.msea.2015.06.034.

[9] J. Mola, B.C. De Cooman, Quenching and partitioning processing of transformable ferritic stainless steels, Scr. Mater. 65 (2011) 834-837. doi:10.1016/j.scriptamat.2011.07.041.

[10] M.J. Santofimia, L. Zhao, R. Petrov, J. Sietsma, Characterization of the microstructure obtained by the quenching and partitioning process in a low-carbon steel, Mater. Charact. 59 (2008) 1758-1764. doi:10.1016/j.matchar.2008.04.004.

[11] C.Y. Wang, J. Shi, W.Q. Cao, H. Dong, Characterization of microstructure obtained by quenching and partitioning process in low alloy martensitic steel, Mater. Sci. Eng. A. 527 (2010) 3442-3449. doi:10.1016/j.msea.2010.02.020.

[12] T.Y. Hsu, Z.Y. Xu, Design of Structure, Composition and Heat Treatment Process for High Strength Steel, Mater. Sci. Forum. 561-565 (2007) 2283-2286. doi:10.4028/www.scientific.net/MSF.561-565.2283.

[13] I. de Diego-Calderón, D. De Knijf, M.A. Monclús, J.M. Molina-Aldareguia, I. Sabirov, C. Föjer, R.H. Petrov, Global and local deformation behavior and mechanical properties of individual phases in a quenched and partitioned steel, Mater. Sci. Eng. A. 630 (2015) 27-35. doi:10.1016/j.msea.2015.01.077.

[14] I. de Diego-Calderón, M.J. Santofimia, J.M. Molina-Aldareguia, M.A. Monclús, I. Sabirov, Deformation behavior of a high strength multiphase steel at macro- and micro-scales, Mater. Sci. Eng. A. 611 (2014) 201-211. doi:10.1016/j.msea.2014.05.068.

[15] J.A. Rodríguez-Martínez, R. Pesci, A. Rusinek, A. Arias, R. Zaera, D.A. Pedroche, Thermo-mechanical behaviour of TRIP 1000 steel sheets subjected to low velocity perforation by conical projectiles at different temperatures, Int. J. Solids Struct. 47 (2010) 1268-1284. doi:10.1016/j.ijsolstr.2010.01.013.

[16] J.A. Rodríguez-Martínez, A. Rusinek, R. Pesci, Experimental survey on the behaviour of AISI 304 steel sheets subjected to perforation, Thin-Walled Struct. 48 (2010) 966-978. doi:10.1016/j.tws.2010.07.005.

[17] M.I. Khan, M.L. Kuntz, Y. Zhou, Effects of weld microstructure on static and impact performance of resistance spot welded joints in advanced high strength steels, Sci. Technol. Weld. Join. 13 (2008) 294-304. doi:10.1179/174329308X271733.

[18] S.C. Hong, J.C. Ahn, S.Y. Nam, S.J. Kim, H.C. Yang, J.G. Speer, D.K. Matlock, Mechanical properties of high-Si plate steel produced by the quenching and partitioning process, Met. Mater. Int. 13 (2007) 439-445. doi:10.3365/MMI.2007.12.439.

[19] M.C. Somani, L.P. Karjalainen, D.A. Porter, R.D.K. Misra, Evaluation of the Behaviour and Properties of a High-Si Steel Processed Using Direct Quenching and Partitioning, Mater. Sci. Forum. 706-709 (2012) 2824-2829. doi:10.4028/www.scientific.net/MSF.706-709.2824.

[20] E.D. Moor, J.G. Speer, D.K. Matlock, J.-H. Kwak, S.-B. Lee, Effect of Carbon and Manganese on the Quenching and Partitioning Response of CMnSi Steels, ISIJ Int. 51 (2011) 137-144. doi:10.2355/isijinternational.51.137.

[21] M. Calcagnotto, D. Ponge, D. Raabe, On the Effect of Manganese on Grain Size Stability and 
Hardenability in Ultrafine-Grained Ferrite/Martensite Dual-Phase Steels, Metall. Mater. Trans. A. 43 (2012) 37-46. doi:10.1007/s11661-011-0828-3.

[22] M.J. Santofimia, T. Nguyen-Minh, L. Zhao, R. Petrov, I. Sabirov, J. Sietsma, New low carbon Q\&P steels containing film-like intercritical ferrite, Mater. Sci. Eng. A. 527 (2010) 6429-6439. doi:10.1016/j.msea.2010.06.083.

[23] M.A. Gervas'ev, A.S. Yurovskikh, S.V. Belikov, O.V. Maslova, A.S. Zhilin, Influence of Al and $\mathrm{Si}$ on austenite formation in $\mathrm{Cr}-\mathrm{Ni}-\mathrm{Mo}$ steel in the intercritical temperature range, Steel Transl. 45 (2015) 658-661. doi:10.3103/S0967091215090065.

[24] R.A. Grange, Estimating the hardenability of carbon steels, Metall. Trans. 4 (1973) 2231-2244. doi:10.1007/BF02669363.

[25] T.H. Courtney, Mechanical Behavior of Materials: Second Edition, Waveland Press, 2005.

[26] D.P. Field, P.B. Trivedi, S.I. Wright, M. Kumar, Analysis of local orientation gradients in $\begin{array}{llllll}\text { deformed } & \text { single } & \text { crystals, } & \text { Ultramicroscopy. } & 103 & \text { (2005) }\end{array}$ doi:10.1016/j.ultramic.2004.11.016.

[27] I.D. Diego-Calderón, D.D. Knijf, J.M. Molina-Aldareguia, I. Sabirov, C. Föjer, R. Petrov, Effect of Q\&P parameters on microstructure development and mechanical behaviour of Q\&P steels, Rev. Metal. 51 (2015) 035.

[28] X.C. Xiong, B. Chen, M.X. Huang, J.F. Wang, L. Wang, The effect of morphology on the stability of retained austenite in a quenched and partitioned steel, Scr. Mater. 68 (2013) 321-324. doi:10.1016/j.scriptamat.2012.11.003.

[29] S. Maropoulos, N. Ridley, Inclusions and fracture characteristics of HSLA steel forgings, Mater. Sci. Eng. A. 384 (2004) 64-69. doi:10.1016/j.msea.2004.05.023.

[30] K.R.F. Andrews, G.L. England, E. Ghani, Classification of the axial collapse of cylindrical tubes under quasi-static loading, Int. J. Mech. Sci. 25 (1983) 687-696. doi:10.1016/0020-7403(83)90076-0.

[31] A.K. Roy, S.R. Kukatla, B. Yarlagadda, V.N. Potluri, M. Lewis, M. Jones, B.J. O'Toole, Tensile properties of martensitic stainless steels at elevated temperatures, J. Mater. Eng. Perform. 14 (2005) 212-218. doi:10.1361/10599490523373.

[32] F. Ozturk, S. Toros, S. Kilic, Tensile and Spring-Back Behavior of DP600 Advanced High Strength Steel at Warm Temperatures, J. Iron Steel Res. Int. 16 (2009) 41-46. doi:10.1016/S1006-706X(10)60025-8.

[33] G.B. Olson, Transformation Plasticity and the Stability of Plastic Flow, in: Deform. Process. Struct., ASM, 1984: pp. 391-424.

[34] G.B. Olson, M. Cohen, Stress-assisted isothermal martensitic transformation: Application to TRIP steels, Metall. Trans. A. 13 (1982) 1907-1914. doi:10.1007/BF02645934.

[35] K. Sugimoto, M. Kobayashi, A. Nagasaka, S. Hashimoto, Warm Stretch-formability of TRIP-aided Dual-phase Sheet Steels, ISIJ Int. 35 (1995) 1407-1414. doi:10.2355/isijinternational.35.1407.

[36] Q. Hao, S. Qin, Y. Liu, X. Zuo, N. Chen, W. Huang, Y. Rong, Effect of retained austenite on the dynamic tensile behavior of a novel quenching-partitioning-tempering martensitic steel, Mater. Sci. Eng. A. 662 (2016) 16-25. doi:10.1016/j.msea.2016.03.007.

[37]D. De Knijf, C. Föjer, L.A.I. Kestens, R. Petrov, Factors influencing the austenite stability during tensile testing of Quenching and Partitioning steel determined via in-situ Electron Backscatter Diffraction, Mater. Sci. Eng. A. 638 (2015) 219-227. 
doi:10.1016/j.msea.2015.04.075.

[38] H.P. Stüwe, The work necessary to form a ductile fracture surface, Eng. Fract. Mech. 13 (1980) 231-236. doi:10.1016/0013-7944(80)90056-9.

[39] M.A. Chowdhury, M.K. Khalil, D.M. Nuruzzaman, M.L. Rahaman, The Effect of Sliding Speed and Normal Load on Friction and Wear Property of Aluminum, 11 (2011) 5.

[40] A.K. Ghosh, A method for determining the coefficient of friction in punch stretching of sheet metals, Int. J. Mech. Sci. 19 (1977) 457-470. doi:10.1016/0020-7403(77)90019-4.

[41] T.-S. Yang, T.-C. Hsu, Forming limit analysis of hemispherical-punch stretch forming, J. Mater. Process. Technol. 117 (2001) 32-36. doi:10.1016/S0924-0136(01)01104-9.

[42] V.F. Zackay, E.R. Parker, D. Fahr, R. Busch, The enhancement of ductility in high-strength steels, ASM Trans Quart. 60 (1967) 252-259.

[43] K. Zhang, M. Zhang, Z. Guo, N. Chen, Y. Rong, A new effect of retained austenite on ductility enhancement in high-strength quenching-partitioning-tempering martensitic steel, Mater. Sci. Eng. A. 528 (2011) 8486-8491. doi:10.1016/j.msea.2011.07.049.

[44]L. Wang, J.G. Speer, Quenching and Partitioning Steel Heat Treatment, Metallogr. Microstruct. Anal. 2 (2013) 268-281. doi:10.1007/s13632-013-0082-8.

[45] L. Wang, W. Feng, Development and Application of Q\&P Sheet Steels, Adv. Steels. (2011) 255-258. doi:10.1007/978-3-642-17665-4_25.

[46] X. Chen, C. Niu, C. Lian, J. Lin, The Evaluation of Formability of the 3rd Generation Advanced High Strength Steels QP980 based on Digital Image Correlation Method, Procedia Eng. 207 (2017) 556-561. doi:10.1016/j.proeng.2017.10.1020.

[47] D. Zou, S. Li, J. He, R. Cui, Failure Investigation for QP Steel Sheets under uniaxial and Equal-Biaxial Tension Conditions, J. Phys. Conf. Ser. 734 (2016) 032017. doi:10.1088/1742-6596/734/3/032017.

[48] H. Xie, X. Dong, Q. Wang, F. Peng, K. Liu, X. Wang, F. Chen, J. Wang, Investigation on transient electrically-assisted stress relaxation of QP980 advanced high strength steel, Mech. Mater. 93 (2016) 238-245. doi:10.1016/j.mechmat.2015.11.007.

[49] D. Zou, S. Li, J. He, B. Gu, Y. Li, The deformation induced martensitic transformation and mechanical behavior of quenching and partitioning steels under complex loading process, Mater. Sci. Eng. A. 715 (2018) 243-256. doi:10.1016/j.msea.2018.01.011.

[50] Y. Li, Y. Sun, H. Xiao, H.J. Bong, L. Shi, S. Li, D. Li, S. Ding, R.H. Wagoner, A numerical study on chain-die forming of the AHSS U-channel and contrast with roll forming, Int. J. Mech. Sci. 135 (2018) 279-293. doi:10.1016/j.jjmecsci.2017.11.034. 